\title{
Program Diversifikasi Pemanfaatan Produk Ikan Laut di Kampung Nelayan Danaweria Fak Fak, Papua Barat
}

\author{
Krismi Budi Sienatra ${ }^{{ }^{*}}$, Christina Whidya Utami ${ }^{2}$, Metta Padmalia ${ }^{3}$, \\ Gladys Griselda Gosal ${ }^{4}$, Maria Dini Gilang Prativi 5
}

1, 2, 3, 4, 5 Universitas Ciputra Surabaya

${ }^{1^{*}}$ krismi.budi@ciputra.ac.id, ${ }^{2}$ whidyautami@ciputra.ac.id, ${ }^{3}$ metta.padmalia@ciputra.ac.id, ${ }^{4}$ gladys.gosal@ciputra.ac.id, ${ }^{5}$ dini.prativi@kalbis.ac.id

\begin{abstract}
Abstrak
Fakfak adalah salah satu daerah penghasil ikan untuk diekspor terbesar di Indonesia. Namun tidak semua manfaat tersebut dapat dinikmati oleh para nelayan penangkap ikan khususnya yang masih tradisional. Nelayan tradisional yang menangkap ikan dalam jumlah kecil kesulitan untuk menjual ikan tangkapannya ke pasar produk lokal sehingga menyebabkan hasil tangkapan ikan busuk. Selain itu, produk turunan yang dikelola menjadi abon ikan tidak dikoordinasi dengan baik sehingga terjadi pelabelan ganda. Upaya dalam menyelesaikan masalah ini dilakukan dengan dua cara, pertama, dengan melakukan pengkoordinasian membentuk produk rebranding dengan nilai Papua Heritage untuk mencegah pelabelan ganda dan mempersatukan para produsen. Kedua, dilakukan dengan melakukan workshop pembuatan pallet ikan dari ikan yang membusuk. Pallet ikan ini berfungsi sebagai bahan pakan untuk peternak ayam dan peternak ikan untuk menunjang usaha peternakan yang masih sangat sedikit di Fakfak. Kedua metode ini merupakan salah satu bentuk deversifikasi produk turunan ikan yang dapat dimanfaatkan masyarakat untuk meningkatkan nilai tambah dari hasil tangkapan ikan yang mereka tangkap dalam kapasitas kecil sehingga tetap dapat memberikan kontribusi ekonomi rumah tangga di komunitas kampung nelayan di Fakfak.
\end{abstract}

Kata Kunci: diversifikasi, koperasi nelayan, kampung nelayan

\section{Pendahuluan}

Indonesia adalah negara kepulauan dengan potensi ekonomi yang berasal dari laut khususnya sektor perikanan diperkirakan mencapai 15 milyar US\$ pertahun. Potensi penangkapan ikan yang besar ini sayangnya belum mampu dimanfaatkan sepenuhnya oleh masyarakat tradisional di kampung nelayan di wilayah perairan penghasil ikan di Indonesia. Salah satu wilayah Indonesia yang memiliki potensi perikanan yang bisa dikembangkan adalah kabupaten Fakfak. Potensi sumberdaya alam perikanan dan kelautan merupakan sumberdaya yang paling menonjol di Kabupaten Fakfak terutama dengan keberadaan hutan mangrove, estuaria, terumbu karang dan padang lamun yang masih alami yang menjadi tempat berkembangbiak dan tumbuh hidup aneka ikan dan biota laut. Fakfak sebagai kota kabupaten terbesar di Provinsi Papua Barat memiliki komoditas unggulan dari hasil ikan laut selain pala masih belum mampu dimaksimalkan. 
Belum maksimalnya pemanfaatan potensi laut yang ada di perairan Fakfak dapat dilihat dari kondisi ekonomi di warganya. Hal yang membuat masyarakat tidak mampu memanfaatkan kondisi ini adalah banyak minimnya peralatan dalam hal ini kapal untuk menangkap ikan. Kabupaten Fakfak memiliki 1878 kepala keluarga nelayan yang dimana mereka menangkap ikan dengan menggunakan kapal tradisional dan kapal mesin dengan kapasitas 5-10 GT yang maksimal hanya mampu berlayar radius 4-10 mil. Jika berlayar lebih dari 10 mil dari garis pantai untuk menangkap ikan harus menggunakan kapal diatas 10 GT untuk mencapai radius 10 - 12 mil yang ijin kapalnya harus melakukan perijinan hingga tingkat provinsi dan diatas 12 mil dengan kapal kapasitas 30 GT keatas harus melakukan perijinan hingga kementerian. Masyarakat nelayan yang menggunakan kapal tradisional hanya mampu menangkap ikan dengan rata-rata $5 \mathrm{~kg}$ setiap kali berlayar. Sedangkan dengan menggunakan kapal dengan kapasitas 5-10 GT hanya mampu mengangkut ikan sebesar $50-100 \mathrm{~kg}$.

Masyarakat kampung nelayan di Fakfak umumnya membentuk koperasi - koperasi untuk melakukan koordinasi dalam mendanai nelayan untuk menangkap ikan dan sebagai tempat pengumpulan hasil ikan pertama. Hasil ikan yang dikumpulkan oleh koperasi nelayan di seluruh Fakfak ini nantinya akan dikumpulkan di cold storage Pelabuhan Fakfak sebelum diambil oleh para pembeli ikan dalam partai besar untuk diekspor. Hasil ikan laut di Fakfak ini umumnya meliputi ikan tuna, baby tuna, kakap merah, bawal, muhara, cakalang, dan tengiri yang merupakan jenis-jenis ikan kualitas ekspor. Namun, ikan-ikan jenis tersebut hanya mampu ditangkap di perairan air dalam diatas 5 mil untuk hasil tangkapan yang maksimal. Nelayan yang menggunakan kapal tradisional ini manangkap ikan maksimal sejauh maksimal 5 mil hanya mampu menangkap ikan yang berukuran kecil dengan kuantitas sedikit. Hasil tangkapan ikan yang tidak maksimal ini dengan kualitas ikan yang biasa saja ini hanya mampu untuk dijual di pasar lokal di Fakfak dan dikonsumsi sendiri.

Dalam usaha untuk meningkatkan ekonomi masyarakat nelayan tradisional ini diperlukan usaha untuk meingkatkan nilai dari hasil tangkapan ikan ini. Hal ini diperlukan agar hasil tangkapan ikan ini tidak hanya dijual dalam bentuk segar namun diolah ke produk lain. Program pengembangan kelompok nelayan di pesisir berbeda karena umumnya mereka terbagi kedalam kelompok masyarakat nelayan tangkap, nelayan budidaya, nelayan pengepul, dan nelayan pengolahan ikan (Subagiana et al., 2018). Program pengembangan dengan melakukan diversifikasi produk ikan tangkap ini ditunjukkan ke salah satu kelompok nelayan di Fakfak Barat yaitu kelompok nelayan Koperasi Danaweria. Kegiatan ini dilakukan dengan melakukan survey ke dinas terkait yaitu dinas koperasi dan perekonomian Fakfak dan kementerian Kelautan dan Perikanan Fakfak lalu melakukan kunjungan ke kelompok nelayan koperasi Danaweria Fakfak Barat Kemudian memberikan konsep pengembangan produk yang sesuai dengan potensi dan memberikan nilai tambah bagi kelompok masyarakat nelayan koperasi Danaweria.

\section{Metode Pelaksanaan}

Dalam melaksanakan program pengembangan diversifikasi produk ikan kampung nelayan koperasi Danaweria hal yang dilakukan melalui beberapa tahap dengan rangkaian focus discuss group discussion dan survey lapangan dengan rincian sebagai berikut: 
Tabel 1. Jadwal Kegiatan

\begin{tabular}{lll}
\hline Hari / Tgl & Metode & Tujuan \\
\hline 4 November 2019 & Focus Group Discussion & Dinas Koperasi \\
5 November 2019 & Focus Group Discussion & Dinas Perdagangan Dan Perindustrian \\
5 November 2019 & Focus Group Discussion & Dinas Perikanan Dan Kelautan \\
5 November 2019 & Survey Lapangan & Cold Storage Pelabuhan Fakfak \\
6 November 2019 & Survey Lapangan & Koperasi Nelayan Danaweria \\
7 November 2019 & Workshop penyuluhan & Pasar Besar Fakfak \\
\hline
\end{tabular}

Focus group discussion dengan mendatangani dinas-dinas terkait untuk mengambil informasi dari pejabat pemerintahan terkait keadaan secara makro aktivitas ekonomi dan gambaran penduduk Fakfak bagian barat khususnya yang berprofesi sebagai nelayan. Tim peneliti juga bertemu dengan koperasi nelayan Danawerian distrik Fakfak Barat untuk mendengar situasi dari pihak nelayan. Hasil focus group discussion dan survei lapangan Kemudian dirangkum untuk diberikan solusi yang terbaik untuk membuat diversifikasi produk ikan agar dapat bermanfaat memberikan nilai lebih (Salatan et al., 2018).

\section{Hasil dan Pembahasan}

\section{Dinas Koperasi dan Dinas Perdagangan}

Beberapa produk olahan yang telah diberikan pelatihan yaitu pembuatan abon ikan, bakso, dendeng ikan. Produk olahan ini dibuat oleh mayoritas ibu rumah tangga, dan bukan profesi utama karena mereka biasanya berkebun, jadi bikin olahan ikan kalau ada permintaan saja. Produk perikanan di wilayah Fakfak Barat belum ada PIRT dengan ada satu industri yang skalanya besar yaitu abon ikan dimana mayoritas produk olahan tidak terlalu digemari masyarakat lokal, lebih fokus ke oleh-oleh buat orang luar.

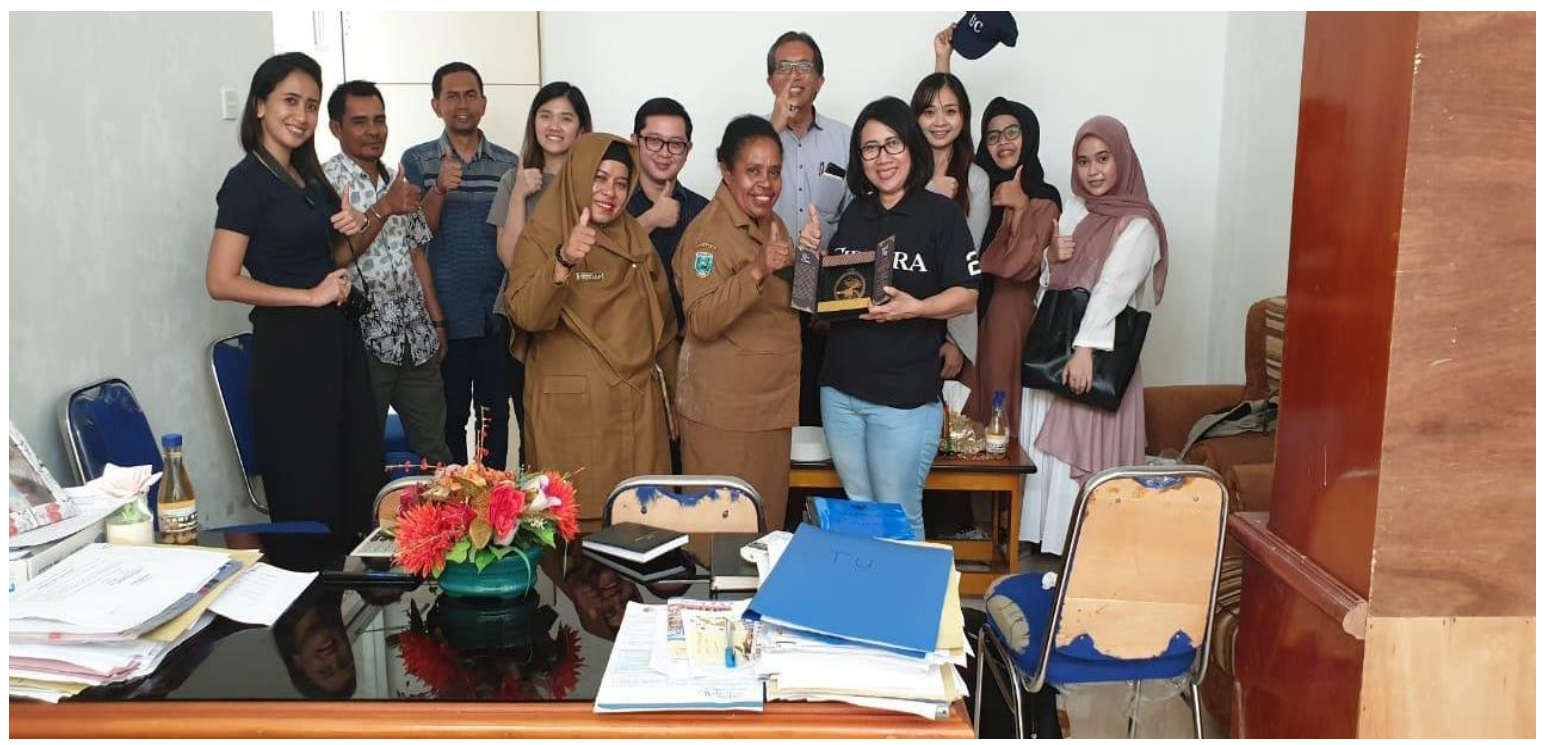

Gambar 1. FGD dengan Dinas Koperasi 
Kendala utama di Fakfak terdapat 7 hal utama yaitu: 1) zonasi untuk ekspor antar pulau banyak titik untuk masuk ke Fakfak 3 bulan sekali, 2) infrastruktur, 3) proses penangkapan yang masih tradisional, 4) tempat penyimpanan tidak memadai, 5) Pelabuhan daerah dengan biaya yang mahal dan dwelling time yang lama, 6) duplikasi pelabelan produk olahan, 7) industry lokal tidak terlalu besar menyerap produk yang hanya sekitar 1-2 ton per bulan.

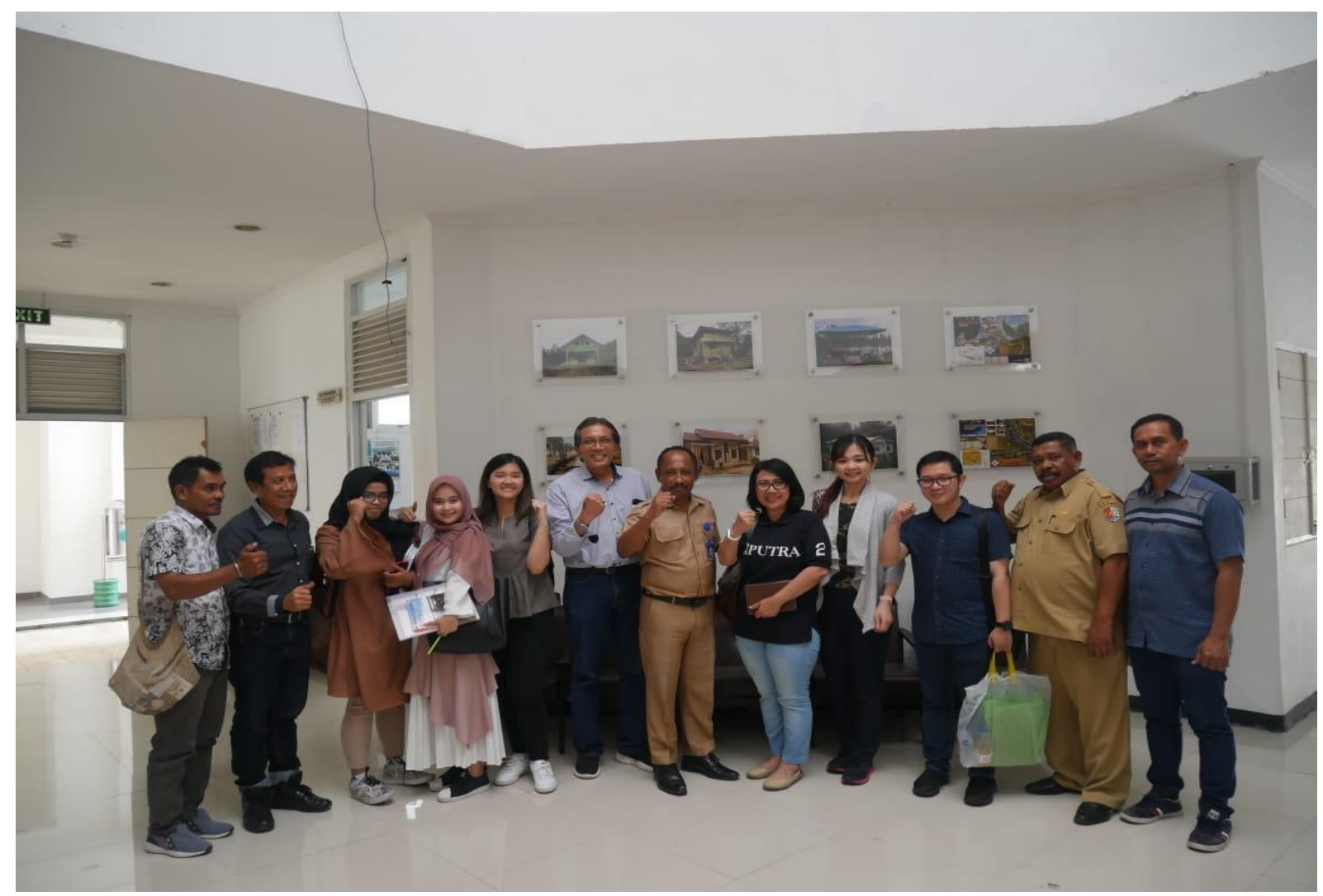

Gambar 2. FGD dengan Dinas Perdagangan

\section{Dinas Perikanan dan Kelautan dan Tempat Penampungan Ikan}

Wilayah Fakfak seluas 1420 m2 terdiri dari 142 kampung dan 124 kampung ada di pesisir dan pulau dengan mata pencaharian utama yaitu petani dan menangkap ikan di laut. Apabila masuk musim buah pala maka nelayan memilih untuk bekerja di kebun buah pala juga setelahnya baru melaut lagi, kecuali pada daerah yang memang ada di daerah laut seperti distrik Arguni. Fakfak berbeda dengan Sorong yang bisa melebihi kapasitas produksi ikannya karena keterbatasan sarana dan prasarana khususnya tempat penampungan ikan dan es untuk pengawetan ikan. Jenis ikan yang terbanyak: tuna, tenggiri, cakalang, tongkol yang mensupply ke Sorong, Timika, Manokwari. Perijinan surat ijin kapal laut yang dialihkan ke tingkat provinsi sehingga lebih lama hal ini berdampak seperti ada bantuan kapal kapasitas 10 GT namun tidak bisa digunakan karena proses ijin yang lama dan belum memiliki SIM laut. 


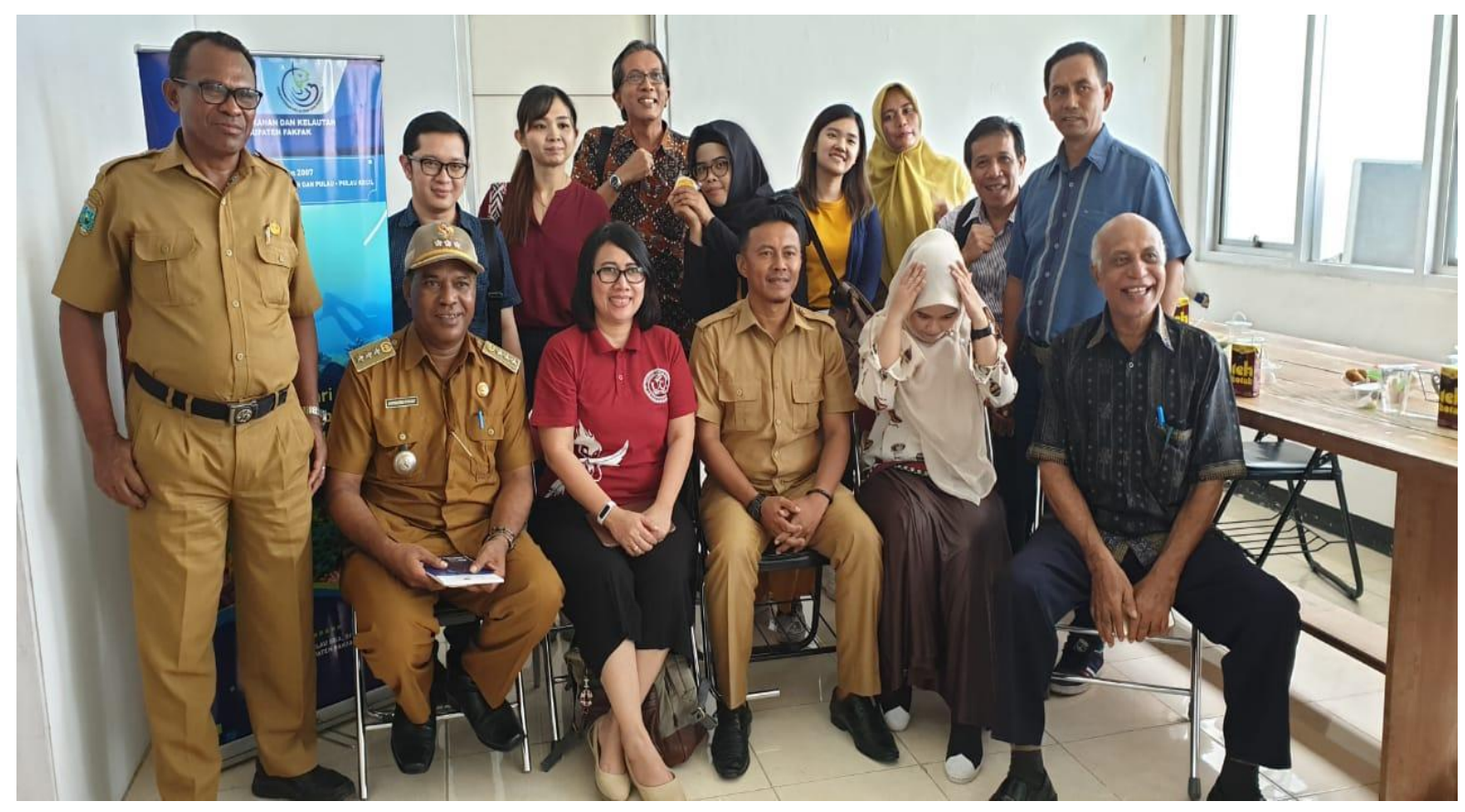

Gambar 3. FGD dengan Dinas Perikanan dan Kelautan

Hasil focus group discussion dari pengelola tempat penampungan ikan menemukan bahwa TPI yang ada di Pelabuhan hanya mampu memuat ikan sebanyak maksimal 100 ton ikan. TPI yang ada tidak mampu untuk menampung ikan diseluruh Fakfak. Karena ikan yang masuk kedalam TPI ini hanya ikan yang dipasok dari kapal-kapal dibawah 10 GT. Kapal yang memiliki kapasitas diatas 10 GT menangkap ikan untuk langsung dikirimkan ke kapal-kapal besar di tengah lautan untuk langsung dikirimkan ekspor atau dibawa ke Pelabuhan Indonesia Barat.

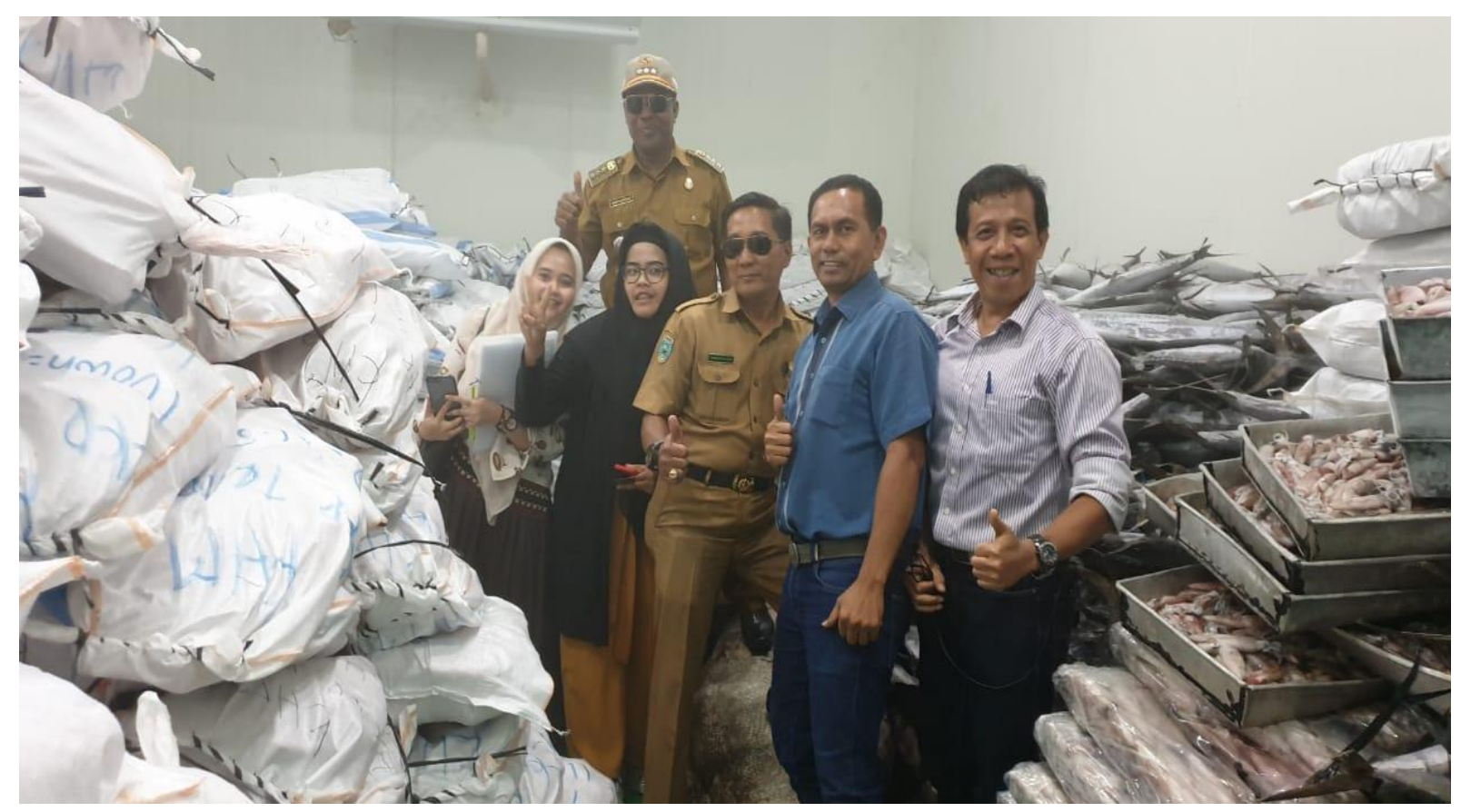

Gambar 4. Tempat Penampungan Ikan Fakfak 
Tabel 2. Tahapan Pelaksanaan \& Pihak Yang Terkait

\begin{tabular}{ll}
\hline Tahapan Pelaksanaan & Keterlibatan Pihak Terkait \\
\hline Mencari partner peternak ayam dan peternak ikan & Pemda \\
$\begin{array}{l}\text { Bekerjasama dengan koperasi atau nelayan untuk bahan } \\
\text { baku limbah ikan busuk }\end{array}$ & $\begin{array}{l}\text { Pemda, Dinas Koperasi, Dinas } \\
\text { Perdagangan }\end{array}$ \\
$\begin{array}{l}\text { Menetapkan SOP dan pelatihan mengenai proses } \\
\text { produksi }\end{array}$ & Pemda \\
\hline
\end{tabular}

\section{Kampung Nelayan Koperasi Danaweria}

Koperasi nelayan dibentuk untuk memfasilitasi anggota nelayan yang kekurangan modal khususnya bahan bakar kapal dan berfungsi menampung hasil tangkapan ikan. (Nuryanto \& Haryono, 2017). Koperasi nelayan Danaweria hanya memiliki 35 anggota koperasi dengan kapasitas setiap nelayan dalam sekali melakukan penangkapan ikan hanya berkisar $10 \mathrm{~kg}$ hingga maksimal $100 \mathrm{~kg}$. Hal ini disebabkan karena kapal yang digunakan masih tradisional dan relative kecil. Kendala yang dihadapi adalah koperasi hanya mampu memproduksi es sebagai bahan untuk pengawetan hasil tangkapan ikan dalam jumlah kecil karena mesin pembuat es tidak mampu membuat es dalam bentuk balok besar. Hal ini berakibat ada ikan yang menjadi busuk karena kekurangan es.

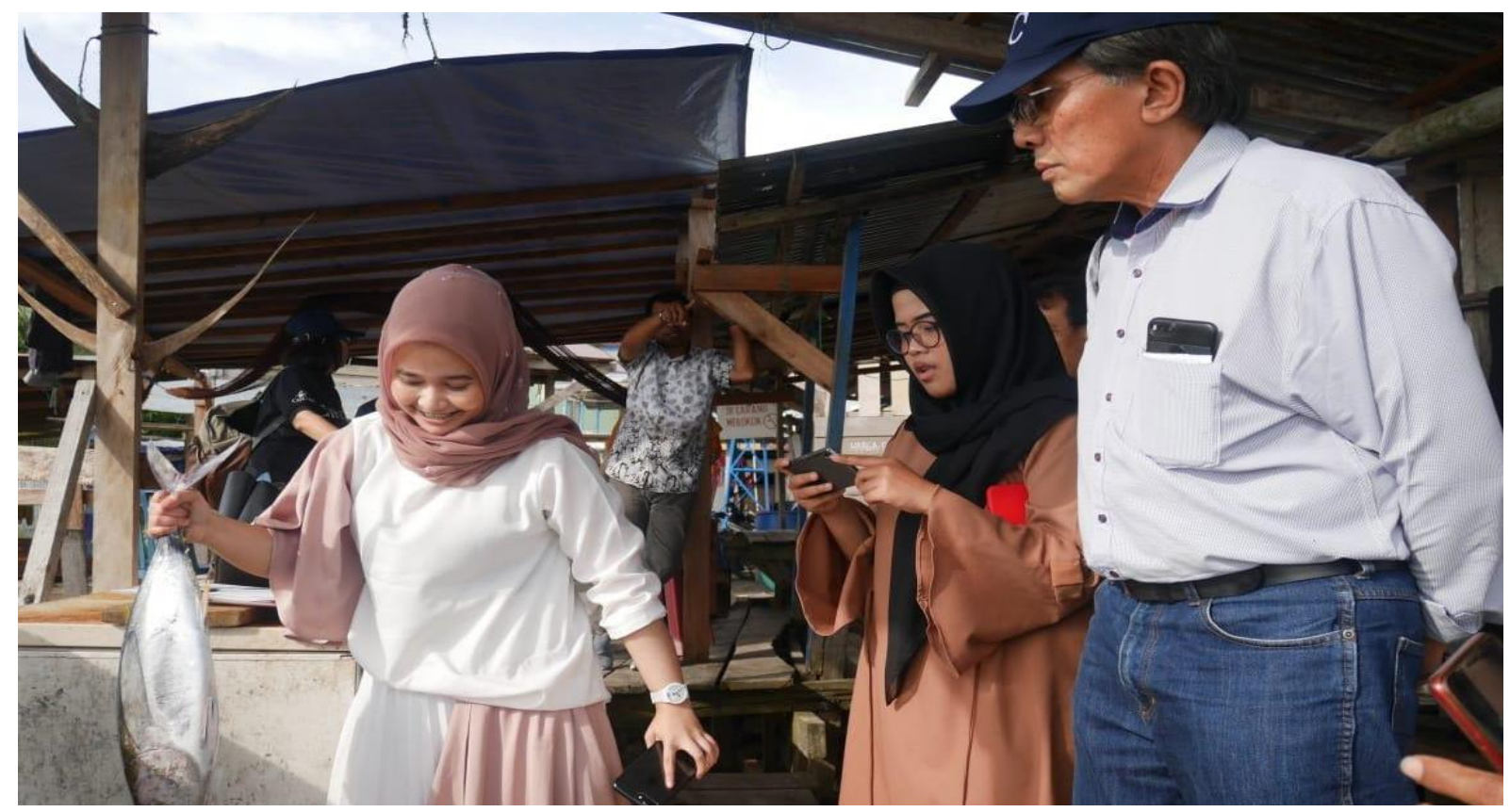

Gambar 5. Survey Lapangan Koperasi Danaweria

\section{Solusi untuk Diversifikasi Produk Olahan Value Added}

Solusi yang diberikan dengan melihat permasalahan yang ada dari informasi dinas dan kelompok nelayan terdapat dua masalah kaitan dengan pengolahan produk olahan turunan pertama yaitu produk olahan yang telah dibuat masih individu kelompok dan tidak memiliki pelabelan yang sama. Kedua permasalahan yang ada karena keterbatasan pasokan es terbatas membuat ikan menjadi busuk dan dibuang begitu saja. 
Solusi pertama adalah dengan melakukan re-branding produk dengan tema Papua Heritage Values dan solusi kedua adalah memanfaatkan ikan busuk diolah menjadi pallet ikan. Re-branding produk dengan tema Papua Heritage Values diperlukan karena brand yang kuat dapat membuat produk atau jasa mudah dikenal dan dijual kepada konsumen atau pemakai. Upaya pembuatan diferensiasi merek yang kuat kepada produk turunan perikanan wilayah Fakfak mendasari diusulkannya solusi strategi pembentukan branding untuk produk-produk turunan perikanan di wilayah Fakfak dengan lebih menyeluruh dengan mengangkat konsep kearifan lokal Papua. Strategi branding ini bisa meliputi penamaan produk, design packaging, social media management, digital advertising, dan strategi lainnya. Dengan strategi yang tepat, diharapkan akan terciptanya brand awareness akan produk turunan perikanan Fakfak yang lebih luas dan akan berdampak pada peningkatan penjualan dan perolehan profit (Sienatra \& Pranedya, 2020).

Tahapan-tahapan yang harus dilakukan agar solusi ini terlaksana:

a. Mengkomunikasikan solusi kepada Pemda setempat khususnya Dinas Koperasi dan Dinas Perdagangan guna menentukan list produk yang akan dibranding.

b. Menentukan Unique Selling Point dari setiap produk turunan perikanan pilihan yang akan dibranding.

c. Menetapkan budget dan anggaran rebranding.

d. Melakukan pelatihan branding dan promosi kepada stake holder produk olahan perikanan Fakfak

e. Melengkapi dukungan infrastruktur berupa dukungan sosial media dan alat-alat promosi terbaru

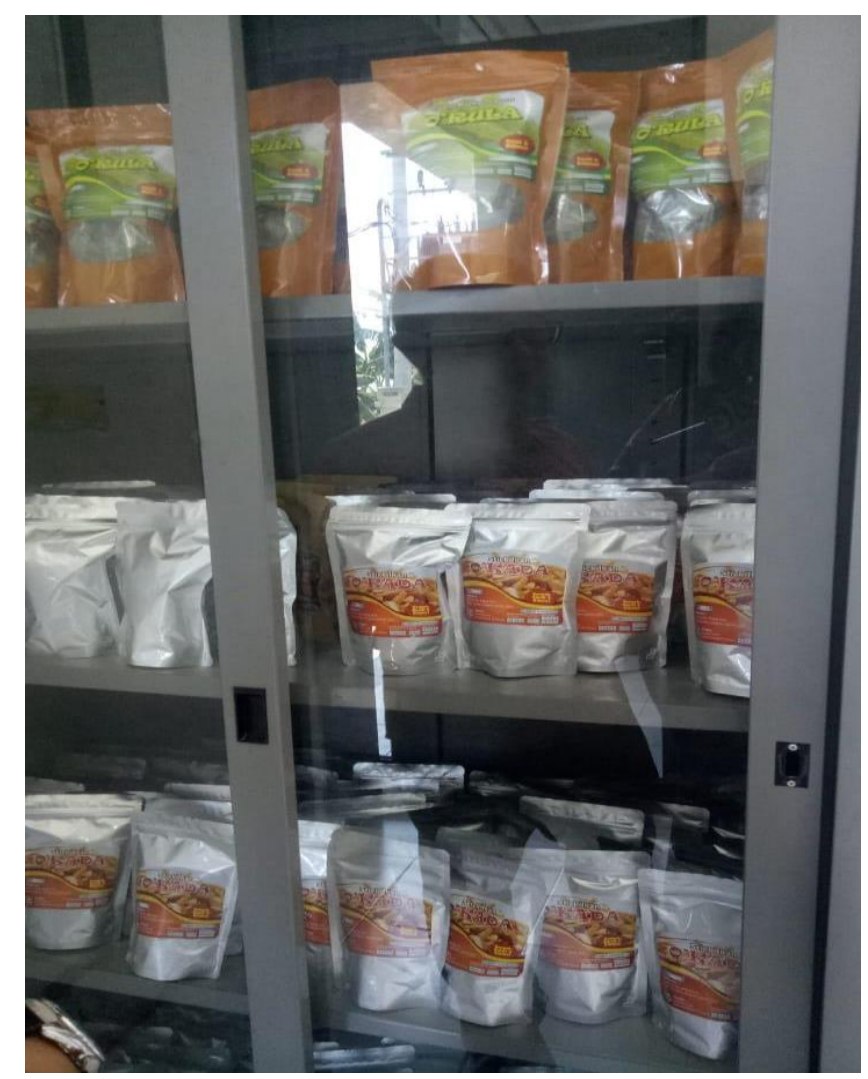

Gambar 6. Produk Olahan Rebranding 
Solusi kedua adalah pembuatan pallet ikan dimana solusi ini menangkap salah satu keluhan dari nelayan di kampung-kampung adalah banyaknya ikan busuk yang tidak memiliki nilai dan akhirnya dibuang. Solusi terakhir untuk masalah ini adalah untuk memanfaatkan ikan busuk yang dibuang menjadi produk yang memiliki daya jual, berupa pellet ikan. Pallet ikan ini dapat digunakan untuk bahan makan peternak ikan dan peternak ayam di Fakfak. Fakfak sebagai daerah penghasil ikan sangat sedikit peternak ayam yang tersedia sehingga dengan adanya bahan pakan ayam dapat mendorong masyarakat Fakfak untuk membuka peternakan ayam untuk memasok kebutuhan daging ayam untuk Fakfak sendiri tanpa perlu bergantung dari daerah lain.

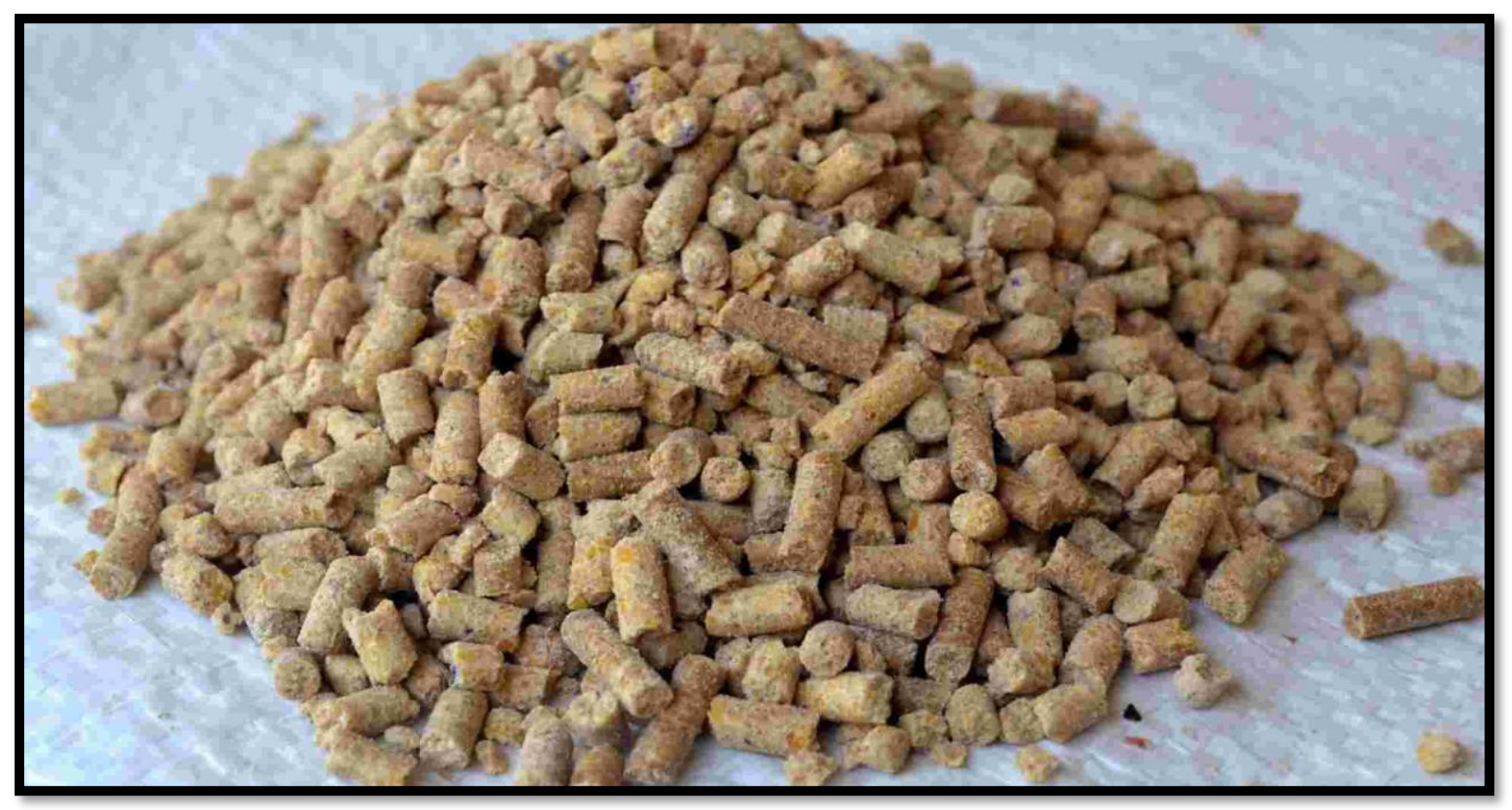

Gambar 7. Pellet yang Diolah dari lkan Busuk

\section{Kesimpulan}

Program diversifikasi pemanfaatan produk ikan laut khususnya limbah ikan laut untuk menjawab sedikit persoalan yang ada di kampung nelayan di Fakfak. Permasalahan yang kompleks dalam memaksimalkan potensi sumber daya alam laut perlu upaya sinergi dari pemerintah pusat, pemerintah daerah, warga lokal, dan pihak investor. Namun hal kecil dapat dilakukan untuk meningkatkan nilai tambah dari produk ikan laut yang tidak hanya berupa bahan mentah namun menjadi produk olahan. Permasalahan mikro yang ditemui dari produk olahan yang tersedia adalah adanya pelabelan ganda dimana tidak ada sinergi dari pihak yang mengkoordinasi menjadi satu industri pengolahan produk turunan seperti abon ikan dan permasalahan lain adalah kurangnya pasokan es yang menyebabkan ikan menjadi busuk.

Permasalahan mikro ini dapat diatasi dengan dua cara yaitu dengan membuat kelompok produksi produk olahan dengan re-branding dengan tema Papua Heritage untuk mengangkat citra produk olahan asal Fakfak. Cara kedua yang digunakan adalah dengan memanfaatkan limbah ikan busuk menjadi pallet dimana pallet ini dapat digunakan untuk bahan pakan peternak ayam dan peternak ikan. Pemanfaatan pallet ini 
dapat mendorong munculnya sektor usaha baru dalam area ternak ayam dan ternak ikan yang masih sangat jarang di Fakfak.

\section{Ucapan Terimakasih}

Ucapan terima kasih kepada British Petroleum sebagai institusi yang memfasilitasi kegiatan ini untuk eksplorasi di Fakfak.

\section{Referensi}

Nuryanto, N., \& Haryono, H. (2017). Pemberdayaan Masyarakat Nelayan Pesisir Pantai Utara Jawa Tengah Melalui Koperasi Nelayan Dan E-Commerce. Jurnal Sains dan Teknologi Maritim, 17(1). https://doi.org/10.33556/jstm.voi1.157

Salatan, S., Manoppo, V. E. N., \& Darwisito, S. (2018). Strategi Pemberdayaan Masyarakat Nelayan Soma Pajeko Di Kecamatan Salibabu Kabupaten Kepulauan Talaud Sulawesi Utara. Jurnal Sosial Ekonomi Kelautan Dan Perikanan, 13(1), 87. https://doi.org/10.15578/jsekp.v13i1.6851

Sienatra, K.B. \& Pranedya, A. (2020). Penggunaan Brand Awareness sebagai Mediasi Antara Advertising dan Purchase Decision Produk Fashion Online. Jurnal Manajemen Bisnis Dan Kewirausahaan, 4(6), 340-345. https://doi.org/10.24912/jmbk.v4i6.9047

Subagiana, I. G. M., Artatanaya, I. G. L. S., \& Wijayati, N. L. M. (2018). Model Pemberdayaan Ekonomi Masyarakat Pesisir (PEMP) pada Tiga Perkampungan Nelayan Air Kuning, Pengambengan dan Candi Kusuma Kabupaten Jembrana Propinsi Bali (Suatu Studi Komparatif). Jurnal Bisnis dan Kewirausahaan, 14(2).

https://doi.org/10.31940/jbk.v14i2.1042 